Research Article

\title{
Spatiotemporal Evolution and Influencing Factors of China's Agricultural Environmental Efficiency
}

\author{
Qian Jia (1D) $1,2,3$ \\ ${ }^{1}$ North China University of Water Resources and Electric Power, Zhengzhou 450000, China \\ ${ }^{2}$ Henan Engineering Research Center of Water Pollution and Soil Damage Remediation, Zhengzhou 450000, China \\ ${ }^{3}$ Henan Key Laboratory of Water Environment Simulation and Treatment, Zhengzhou 450000, China
}

Correspondence should be addressed to Qian Jia; huashuijiaqian@126.com

Received 19 April 2021; Revised 17 May 2021; Accepted 24 May 2021; Published 2 June 2021

Academic Editor: Guangdong Wu

Copyright ( 2021 Qian Jia. This is an open access article distributed under the Creative Commons Attribution License, which permits unrestricted use, distribution, and reproduction in any medium, provided the original work is properly cited.

\begin{abstract}
Taking the 30 Chinese provinces in 2000-2018 as the objects, this paper measures their agricultural environmental efficiencies (AEEs) with slack-based measure (SBM) containing an undesired output. Then, the features of the spatiotemporal evolution of AEE in China were explored on ArcGIS, and the factors affecting the AEE were analyzed with a geodetector. The results show that there is a huge provincial gap in AEE across China; most provinces with a high AEE belong to eastern coastal region, while most inland provinces had a relatively low AEE. Except for a few years, the AEEs in eastern, central, and western regions changed very slightly, and the eastern region had a higher AEE level than central and western regions. The results of spatiotemporal evolution show that, with the elapse of time, the high-AEE provinces gradually shifted to the inland; the AEE trend varied from province to province; the provinces were highly polarized in terms of AEE. The AEE is mainly affected by the following factors: fiscal expenditure, fertilizer intensity, pesticide intensity, and economic growth.
\end{abstract}

\section{Introduction}

Since the reform and opening-up, China has achieved remarkable achievements in agricultural development. The agricultural modernization of China is accompanied by a continuous growth in mechanization level. As a result, the food yield has been significantly improved, and the production of profitable economic crops has been increased step by step. Suffice to say, agriculture, as the pillar of national economy, fills the food bowls of the 1.4 billion population and underpins the construction and development of the national economy. However, agriculture in China still follows the production model of high consumption, high input, and high waste. Lots of chemical fertilizers, pesticides, and diesel are consumed in agricultural production activities. Thus, a huge number of resources is expended, and pollutants are discharged in large quantities, resulting in an increasingly prominent contradiction between agricultural development and environmental protection.
At present, more than $80 \%$ of farmland in China has exceeded their land bearing capacity. Besides, the high carbon emissions of agricultural production activities pose severe challenges to agricultural eco-environment, food security, and human health. Against this backdrop, it is imminent to promote the sustainable development of agriculture. To coordinate the development between agricultural growth, resource utilization, and eco-environmental protection, it is of great significance to include the pollutants generated in agricultural production into the analysis framework of agricultural environmental efficiency (AEE) and adopt scientific measures to evaluate the current AEE level of China [1-3].

\section{Literature Review}

The emergence of problems in agricultural environment has drawn academic attention towards the AEE. Most relevant studies choose to analyze the AEE of only one country. For example, Thirtle et al. [4] evaluated the 
agricultural environmental production efficiency of South Africa in 1947-1991, with the total factor productivity (TFP) index. By input direction function (IDF), Tamini et al. [5] assessed the technical and environmental efficiencies of 210 farms in Quebec, Canada. Greta et al. [6] analyzed the AEE of Italy based on the directional distance function (DDF).

Some scholars incorporated resource and environmental factors into the traditional evaluation of agricultural production efficiency. For instance, Ruttan [7] and Arcelus and Arocena [8] researched the global agricultural production efficiency under the dual constraints of resource and environment and found that environmental pollution brings a certain efficiency loss to agricultural development. Nanere et al. [9] corrected the agricultural productivity of Australia and learned that the corrected agricultural productivity is, to a certain extent, affected by the cost of environmental damage.

Moreover, some scholars focused their energy on comparing the AEEs between countries. For instance, Nin et al. [10] compared the agricultural environmental production efficiencies of some developing countries. Hoang and Alauddin [11] adopted data envelopment analysis (DEA) model to measure and compare the economic, environmental, and biological efficiencies of agricultural production among members of Organization for Economic Cooperation and Development (OECD). Vlontzos et al. [12] used the DEA model to evaluate the total factor environmental efficiencies of the agricultural sector in European Union (EU) states in 2001-2008 and contrasted the results of different states.

To clarify the paths of AEE improvement, some scholars probed deep into the factors affecting the AEE. Fernandez-Cornejo and Shuway [13] studied the longterm impact of agricultural research investment and international technology transfer on the productivity of agriculture. Dono et al. [14] found that strengthening the management of climate change helps to elevate the environmental development efficiency of agriculture. After evaluating the environmental efficiency of farmlands in the Netherlands, Skevas et al. [15] explored how the AEE is affected by crop subsidy, crop rotation, and weather changes.

So far, fruitful results have been achieved on the measurement of AEE and its influencing factors. But the existing research faces two shortcomings: (1) most AEE evaluations treat the non-point source pollution of agriculture as the undesired output, failing to consider the carbon emission in agricultural production; (2) few studies have tackled the spatiotemporal evolution of the AEE. To solve these problems, this paper sets up an evaluation system for the AEE with agricultural carbon emissions as the undesired output and adopted the slackbased measure (SBM) to evaluate the AEE of each province in China [16]. Furthermore, ArcGIS was introduced to analyze how the provincial AEEs evolved in space and time. Finally, the influencing factors of the AEE were investigated with geodetector.

\section{Methodology}

3.1. SBM. Agricultural production is an important activity of humans to impact and respond to regional eco-environment. The results of agricultural production include both good outputs like food and bad outputs like carbon dioxide and non-point source pollution of agriculture. If the bad outputs are ignored, the AEE evaluation might be biased [17]. If directly included in the evaluation system, the bad outputs cannot be handled by early models like Charnes-CooperRhodes (CCR) model and Banker-Chames-Cooper (BCC) model, which follow the maximum output hypothesis.

To solve the problem, Hailu and Veeman [18] directly incorporated bad outputs as the inputs in the efficiency evaluation system, but this practice does not meet the actual situation of production activities. Besides, traditional models like CCR and BCC, as radial, angular measurement methods, are not good at measuring the slackness in inputs and outputs, making it hard to effectively improve efficiency.

Therefore, Tone [19] established a nonradial, nonangular model called SBM. On the one hand, the model examines the slackness of inputs and outputs, facilitating efficiency improvement; on the other hand, the model perfectly solves the bad outputs in agricultural production. This paper intends to include agricultural carbon emissions as a bad output of AEE. The traditional CCR and BCC models cannot effectively evaluate efficiencies in the presence of bad output (s). This problem is perfectly solved by the SBM. To this end, this paper chooses to evaluate China's AEE using the SBM.

Suppose the target production system contains $n$ decision-making units (DMUs). During the operation of each DMU, $T$ production elements $X=\left(x_{1}, x_{2}, \ldots\right.$, $\left.x_{t}\right) \in R_{+}^{T}$ are needed to produce $U$ desired outputs $Y=$ $\left(y_{1}, y_{2}, \ldots, y_{u}\right) \in R_{+}^{U}$ and $V$ undesired outputs $B=\left(b_{1}, b_{2}, \ldots, b_{v}\right) \in R_{+}^{V}$. Let $Q=\{(x, y, b): x$ can produce $y$ and $b\}$ be the set of all possible production scenarios and $\mathrm{DMU}_{k}=\left(x_{k}, y_{k}, b_{k}\right)$ be the $k$-th DMU to be estimated. Then, the SBM to evaluate the efficiency of the $k$-th DMU $\mathrm{DMU}_{k}$ can be established as

$$
\begin{aligned}
& \sigma^{*}=\min \frac{1-(1 / T) \sum_{t=1}^{T}\left(s_{t}^{x-} / x_{t k}\right)}{1+(1 / U+V)\left(\sum_{u=1}^{U}\left(s_{u}^{y+} / y_{u k}\right)+\sum_{v=1}^{V}\left(s_{v}^{b-} / b_{v k}\right)\right)}, \\
& \text { s.t. } \quad x_{t k}=\sum_{k=1}^{n} x_{t k} \lambda_{k}+s_{t}^{x-}, \quad t=1, \ldots, T \\
& y_{u k}=\sum_{k=1}^{n} y_{u k} \lambda_{k}-s_{u}^{y+}, \quad u=1, \ldots, U \\
& b_{v k}=\sum_{k=1}^{n} b_{v k} \lambda_{k}+s_{v}^{b-}, \quad v=1, \ldots, V \\
& \lambda>0, s_{t}^{x-}, s_{u}^{y+}, s_{v}^{b-} \geq 0
\end{aligned}
$$

where $\sigma *, T, U$, and $V$ are the AEE (evaluation target), the number of inputs, the number of desired outputs, and the 
number of undesired outputs, respectively, $s_{t}^{x-}, s_{v}^{b-}$ are the redundancy of inputs and undesired outputs, respectively, $s_{u}^{y+}$ is the deficiency of desired outputs, $\left(x_{t k}, y_{u k}, b_{v k}\right)$ is the input-output of $\mathrm{DMU}_{k}, \lambda$ is the weight of $\mathrm{DMU}_{k}, \sigma^{*}$ is an index in the range of $[0,1]$ : if $\sigma^{*}=1$, no input or output is redundant or deficient, and $\mathrm{DMU}_{k}$ is on the efficient frontier of DEA; if $0<\sigma^{*}<1$, at least one of $s_{t}^{x-}, s_{u}^{y+}, s_{v}^{b-}$ is nonzero; i.e., the $\mathrm{DMU}_{k}$ is not on the efficient frontier of DEA.

3.2. Geodetector Model. As an important statistical approach, geodetector has been widely used in nature and social sciences. It can not only reveal the spatial differentiation of AEE but also disclose the factors leading to the differentiation. The principle of the model is as follows: if the dependent variable is closely correlated with an independent variable, i.e., the change of dependent variable is greatly affected by the independent variable, then the two variables are strongly similar in spatial distribution. Inspired by Wang et al. [20], geodetector can be expressed as

$$
q=1-\frac{1}{N \sigma^{2}} \sum_{z=1}^{L} N_{z} \sigma_{z}^{2}
$$

where $L$ is the number of layers/classes of AEE influencing factors, $N$ is the number of units in the region, $N_{z}$ is the number of units on layer $h, \sigma^{2}$ and $\sigma_{z}^{2}$ are the discrete variances of the $\mathrm{AEE}$ of the region, and the $\mathrm{AEE}$ on layer $h$, $\mathrm{q}$ is the influence of each factor on AEE. The $q$ value falls between 0 and 1 ; the closer it is to 1 , the greater the influence of the factor on AEE is; the closer it is to 0, the smaller the influence of the factor on AEE is.

3.3. Inputs and Outputs. In this paper, the AEE is a technical efficiency that incorporates agricultural environment and resources into the analysis framework. It is defined as the largest agricultural output and the smallest agricultural pollutant emissions under fixed agricultural production inputs. Therefore, an evaluation system was established to measure the inputs and outputs of the AEE. Table 1 provides the details on each input and output.

Drawing on Greta et al. [6] and data availability, the inputs were determined as labor input, land input, mechanical input, fertilizer input, and agricultural irrigation. Specifically, labor input refers to the number of employees of agriculture, forestry, animal husbandry, and fishery (AFAF) in each province; land input was measured by the total sowing area of crops in each province; mechanical input was substituted by the total mechanical power of agriculture in each province; fertilizer input was characterized by the pure amount of agricultural fertilizer applied in each province; agricultural irrigation was measured by the effective irrigation area of agriculture in each province.

The outputs were divided into desired and undesired output. The desired output is the total output of AFAF in each province. The AFAFs in relevant statistical yearbooks are nominal values, including the price factor. To eliminate the effect of deflation, the gross domestic product (GDP) index was adopted to deflate the total AFAF output to the actual AFAF output with the constant price of 2000.

The undesired output is the environmental pollutant generated during agricultural production. With the mechanization of China's agricultural production, carbon dioxide becomes the leading pollutant generated by agricultural production. Meanwhile, the greenhouse effect brought by carbon dioxide has an increasing impact on agricultural production. Hence, this paper chooses agricultural carbon emissions as the undesired output to measure the AEE. Referring to Johnson et al. [21], every agricultural production activity, ranging from fertilizing, ploughing, and irrigation, could generate carbon dioxide. Inspired by their research, this paper holds that agricultural carbon emissions mainly come from three paths: (1) the indispensable production elements of agriculture, including fertilizer, pesticide, agricultural film, and diesel, which produces lots of carbon dioxide; (2) ploughing, a key operation in agricultural production, which emits a huge amount of organic carbon to the air; (3) the consumption of electricity and other energies in agricultural irrigation, which is also a large carbon emitter. Therefore, the agricultural carbon emissions can be estimated by

$$
C=\sum C_{i}=\sum E_{i} * \gamma_{i}
$$

where $C$ is the total amount of carbon dioxide generated in agricultural activities, $C_{i}$ is the carbon emissions of each carbon source (six carbon sources were selected, namely, fertilizer, pesticide, agricultural film, diesel, ploughing, and agricultural irrigation), $E_{i}$ is the number of each carbon source, $\gamma_{i}$ is the carbon emission coefficient of each carbon source. Referring to Dubey and Lal [22], the carbon emission coefficients of fertilizer, pesticide, agricultural film, diesel, ploughing, and agricultural irrigation were set to $0.8956 \mathrm{~kg} /$ $\mathrm{kg}, 4.9341 \mathrm{~kg} / \mathrm{kg}, 5.18 \mathrm{~kg} / \mathrm{kg}, 0.5927 \mathrm{~kg} / \mathrm{kg}, 3.126 \mathrm{~kg} / \mathrm{hm}^{2}$, and $25 \mathrm{~kg} / \mathrm{hm}^{2}$, respectively.

3.4. Influencing Factors. The AEE measurement involves agricultural environment and resources. Therefore, the AEE is greatly affected by a series of factors, such as economic, social, technology, and institution factors. In light of the literature, this paper determines seven factors that may affect the AEE: economic growth (X1), capitalization level (X2), fertilizer intensity (X3), pesticide intensity (X4), agricultural planting structure (X5), agricultural scientific progress (X6), and fiscal expenditure (X7). The meaning of each factor is given in Table 2.

3.5. Data Sources. Considering data availability and completeness, the sample period was set to 2000-2018, and the samples were determined as 30 provinces in China. Tibet, Hong Kong, Macao, and Taiwan were not considered, owing to the severe lack of data on multiple indices. The data 
TABLe 1: Input-output system of the AEE.

\begin{tabular}{lccc}
\hline Type & Name & Meaning & Unit \\
\hline \multirow{4}{*}{ Inputs } & Labor input & Total number of AFAF employees & 10,000 persons \\
& Land input & Total sowing area of crops & 1,000 hectares \\
& Mechanical input & Total mechanical power of agriculture & $10,000 \mathrm{~kW}$ \\
& Fertilizer input & Pure amount of agricultural fertilizer applied & 10,000 tons \\
Agricultural irrigation & Effective area of agricultural irrigation & 1,000 hectares \\
\hline \multirow{2}{*}{ Outputs } & Total AFAF output & Actual AFAF output with the constant price of 2000 & 100 million yuan \\
& Agricultural carbon emissions & Carbon emissions estimated by formula (3) & 10,000 tons \\
\hline
\end{tabular}

sources for the inputs, outputs, and influencing factors include China Statistical Yearbooks, Rural Statistical Yearbooks of China, China Environment Yearbooks, and the local statistical yearbooks of the 30 provinces, all of which were released in 2001-2009.

\section{Results and Discussion}

4.1. Measuring Results on the AEE. Based on the inputoutput evaluation system of the AEE and the data on each input and output, this paper measures the AEEs of the 30 Chinese provinces in 2000-2018. The results in Table 3 show a clear disparity between the provinces in AEE.

Beijing and Hainan fell on the efficient frontier throughout the sample period, with a mean AEE of 1. Shanghai fell on that frontier in most years but failed to reach the frontier in a few years. Guangdong, Fujian, Liaoning, and Tianjin achieved relatively high mean AEEs $(>0.8)$ in the sample period. The above provinces all realized desirable AEEs, and all belong to the economically developed coastal region in eastern China.

On the contrary, Hebei, Henan, Heilongjiang, Shaanxi, Anhui, Gansu, Shanxi, and Ningxia had relatively low mean AEEs $(<0.6)$ in the sample period. The mean AEEs of Shaanxi and Ningxia were particularly low, standing at 0.4569 and 0.4562 , respectively. There is a huge potential for them to improve their AEEs in future.

In short, most Chinese provinces with a high AEE belong to eastern coastal region, while most inland provinces had a relatively low AEE. To realize agricultural sustainable development, China must pay attention to the agricultural environment and resources in central and western provinces.

To further analyze the regional difference of AEE in China, Figure 1 presents the AEE trends across the country and in eastern, central, and western regions during 2000-2018. In terms of temporal evolution, the nationwide AEE and the AEEs in the three regions did not change greatly in the sample period, except for a slight variation in a few years (2014). Besides, the three regions exhibited a certain difference in AEE. In the sample period, the mean $\mathrm{AEE}$ in eastern region was as high as 0.8276 , far greater than the national average of 0.6998; the mean AEEs in central and western regions were 0.6124 and 0.6356 , and both are below the national average. To sum up, China had a generally low $\mathrm{AEE}$, and the AEE in eastern region was much higher than that in central or western region.
There are two main reasons for the above results. On the one hand, since the reform and opening-up, eastern region modernized agriculture at a far faster speed than central and western regions. The agricultural productivity in this region has been significantly improved, thanks to the adequate capital, advanced agricultural machinery, and modern technology of agricultural production. That is why the eastern region outputs far more agricultural products than the central and western regions. On the other hand, the agricultural eco-environment of the central and western regions is more vulnerable than that of eastern region. The two regions are lacking in farmland water conservancy and road facilities. Coupled with the poor environmental awareness of local farmers, these factors contribute to the poor performance of the two regions in AEE.

4.2. Spatiotemporal Evolution of AEE. The AEEs of the 30 provinces were divided into 5 levels and given different colors (Figure 2) on ArcGIS 10.4.1. The results of 2000 and 2018 were selected for comparative analysis. In terms of space, high AEE provinces shifted towards the inland in central and western regions from 2000 to 2018. In terms of time, there were 4 first-level provinces in both 2000 and 2018; the number of second-level provinces increased from 4 in 2000 to 8 in 2018; the number of third-level provinces dropped deeply from 10 in 2000 to 7 in 2018; the number of provinces fell from 9 in 2000 to 6 in 2018; the number of fifth-level provinces increased from 3 in 2000 to 5 in 2018. Overall, most provinces belong to the low-efficient third to fifth levels, whether in 2000 or 2018 . Hence, most provinces in China had relatively low AEEs and were highly polarized in terms of AEE.

4.3. Influencing Factors of the AEE. Based on formula (2) and Table 2, four time nodes were selected, including 2000, 2006, 2012 , and 2018 , to naturally divide the influencing factors into five categories. Then, geodetector was adopted to analyze each influencing factor. The results are recorded in Table 4.

According to the results of Table 4, the different factors exerted different impacts on China's AEE through the years. By multiyear average, the influencing factors of China's AEE can be ranked in turn as fiscal expenditure, fertilizer intensity, pesticide intensity, economic growth, agricultural planting structure, agricultural scientific progress, and capitalization level. Among them, the influence of four 
TABLE 2: Influencing factors of the AEE.

\begin{tabular}{|c|c|c|}
\hline Index layer & Formula & Unit \\
\hline Economic growth $(\mathrm{X} 1)$ & Total AFAF output/total rural population & $\begin{array}{l}10,000 \text { yuan/ } \\
\text { person }\end{array}$ \\
\hline Capitalization level (X2) & Fixed asset investment of AFAF/number of AFAF employees & $\begin{array}{l}10,000 \text { yuan/ } \\
\text { person }\end{array}$ \\
\hline Fertilizer intensity (X3) & Pure amount of agricultural fertilizer applied/total sowing area of crops & Ton/hectare \\
\hline Pesticide intensity (X4) & Total amount of pesticide applied/total sowing area of crops & Ton/hectare \\
\hline $\begin{array}{l}\text { Agricultural planting structure } \\
\text { (X5) }\end{array}$ & Total sowing area of food crops/total sowing area of crops & $\%$ \\
\hline $\begin{array}{l}\text { Agricultural scientific progress } \\
\text { (X6) }\end{array}$ & Internal expenditure on research and development (R\&D)/GDP & $\%$ \\
\hline Fiscal expenditure (X6) & $\begin{array}{c}\text { Fiscal expenditure on agriculture, forestry, and water (AFW) affairs/total fiscal } \\
\text { expenditure }\end{array}$ & $\%$ \\
\hline
\end{tabular}

TABLE 3: Measured AEEs of each province in China during 2000-2018.

\begin{tabular}{|c|c|c|c|c|c|c|c|c|c|c|c|}
\hline Province & 2000 & 2002 & 2004 & 2006 & 2008 & 2010 & 2012 & 2014 & 2016 & 2018 & Mean \\
\hline Beijing & 1.0000 & 1.0000 & 1.0000 & 1.0000 & 1.0000 & 1.0000 & 1.0000 & 1.0000 & 1.0000 & 1.0000 & 1.0000 \\
\hline Hainan & 1.0000 & 1.0000 & 1.0000 & 1.0000 & 1.0000 & 1.0000 & 1.0000 & 1.0000 & 1.0000 & 1.0000 & 1.0000 \\
\hline Shanghai & 1.0000 & 1.0000 & 1.0000 & 1.0000 & 1.0000 & 1.0000 & 1.0000 & 1.0000 & 0.7609 & 0.7714 & 0.9527 \\
\hline Guangdong & 0.8869 & 0.8828 & 0.9207 & 0.9551 & 0.9172 & 0.9044 & 0.8784 & 0.8089 & 0.8467 & 0.8618 & 0.8830 \\
\hline Fujian & 0.9369 & 0.8461 & 0.8733 & 0.8721 & 0.8945 & 0.9049 & 0.8793 & 0.8209 & 0.8674 & 0.8941 & 0.8753 \\
\hline Liaoning & 0.8265 & 0.8091 & 0.8526 & 0.8627 & 0.8683 & 0.8305 & 0.8154 & 0.7646 & 0.7938 & 0.7998 & 0.8217 \\
\hline Tianjin & 0.8495 & 0.7442 & 0.7248 & 0.7492 & 0.7673 & 0.7745 & 0.7785 & 0.7658 & 1.0000 & 1.0000 & 0.8108 \\
\hline Sichuan & 0.7471 & 0.7867 & 0.8404 & 0.8583 & 0.8122 & 0.7961 & 0.7775 & 0.7078 & 0.7716 & 0.7907 & 0.7850 \\
\hline Jiangsu & 0.7600 & 0.7448 & 0.7750 & 0.7786 & 0.7787 & 0.7862 & 0.7602 & 0.7383 & 0.8156 & 0.8256 & 0.7762 \\
\hline Zhejiang & 0.8208 & 0.7791 & 0.7617 & 0.7633 & 0.7884 & 0.7691 & 0.7656 & 0.7120 & 0.7597 & 0.7661 & 0.7654 \\
\hline Qinghai & 0.7591 & 0.7702 & 0.7815 & 0.7993 & 0.7785 & 0.7372 & 0.7127 & 0.6552 & 0.7356 & 0.7424 & 0.7327 \\
\hline Chongqing & 0.6958 & 0.6959 & 0.7343 & 0.7172 & 0.7423 & 0.7364 & 0.7160 & 0.6784 & 0.7186 & 0.6977 & 0.7128 \\
\hline Jiangxi & 0.7404 & 0.7375 & 0.7317 & 0.7285 & 0.7085 & 0.6844 & 0.6847 & 0.6479 & 0.7095 & 0.7465 & 0.7073 \\
\hline Hunan & 0.7420 & 0.7442 & 0.7145 & 0.7269 & 0.7311 & 0.7104 & 0.6973 & 0.6282 & 0.6903 & 0.6828 & 0.7024 \\
\hline Jilin & 0.7296 & 0.7293 & 0.6919 & 0.7179 & 0.7104 & 0.6801 & 0.6472 & 0.6127 & 0.6940 & 0.7037 & 0.6903 \\
\hline Guizhou & 0.7451 & 0.7288 & 0.7384 & 0.7173 & 0.6928 & 0.6856 & 0.6393 & 0.6016 & 0.6709 & 0.7243 & 0.6867 \\
\hline Guangxi & 0.6623 & 0.6563 & 0.6693 & 0.7095 & 0.7143 & 0.7032 & 0.6842 & 0.6369 & 0.6467 & 0.6517 & 0.6704 \\
\hline Yunnan & 0.6632 & 0.6367 & 0.6569 & 0.6913 & 0.6783 & 0.6450 & 0.6070 & 0.5714 & 0.6008 & 0.6516 & 0.6348 \\
\hline Inner Mongolia & 0.7470 & 0.7185 & 0.6716 & 0.7013 & 0.6108 & 0.5929 & 0.5694 & 0.5305 & 0.5891 & 0.5853 & 0.6262 \\
\hline Shandong & 0.6673 & 0.5900 & 0.5606 & 0.5759 & 0.6430 & 0.6340 & 0.6277 & 0.5836 & 0.6605 & 0.7147 & 0.6194 \\
\hline Hubei & 0.6671 & 0.6389 & 0.6436 & 0.6423 & 0.6251 & 0.6236 & 0.5806 & 0.5352 & 0.6100 & 0.6398 & 0.6157 \\
\hline Xinjiang & 0.7000 & 0.6521 & 0.6261 & 0.6487 & 0.6015 & 0.5867 & 0.5450 & 0.5107 & 0.5769 & 0.5969 & 0.6083 \\
\hline Hebei & 0.6533 & 0.5963 & 0.5405 & 0.5778 & 0.6087 & 0.5991 & 0.5963 & 0.5556 & 0.6479 & 0.6766 & 0.5988 \\
\hline Henan & 0.6170 & 0.6056 & 0.5928 & 0.6232 & 0.6315 & 0.6056 & 0.5887 & 0.5377 & 0.5830 & 0.6059 & 0.5928 \\
\hline Heilongjiang & 0.5932 & 0.5695 & 0.6122 & 0.6169 & 0.5637 & 0.5565 & 0.5345 & 0.5246 & 0.6142 & 0.6187 & 0.5760 \\
\hline Shaanxi & 0.4870 & 0.5336 & 0.5639 & 0.6093 & 0.6086 & 0.5588 & 0.5112 & 0.5103 & 0.5215 & 0.5257 & 0.5653 \\
\hline Anhui & 0.6155 & 0.6065 & 0.5746 & 0.5755 & 0.5720 & 0.5562 & 0.5524 & 0.4927 & 0.5582 & 0.5672 & 0.5578 \\
\hline Gansu & 0.5662 & 0.5318 & 0.5414 & 0.5522 & 0.5274 & 0.5075 & 0.4980 & 0.4423 & 0.4999 & 0.5236 & 0.5131 \\
\hline Shanxi & 0.4931 & 0.4994 & 0.4751 & 0.4693 & 0.4764 & 0.4619 & 0.4540 & 0.4059 & 0.4467 & 0.4514 & 0.4569 \\
\hline Ningxia & 0.4604 & 0.4622 & 0.4460 & 0.4710 & 0.4411 & 0.4588 & 0.4219 & 0.3922 & 0.4586 & 0.4678 & 0.4562 \\
\hline
\end{tabular}

Note. For the lack of space, only the AEEs in even-numbered years are given in the above table.

factors gradually weakened, and that of three gradually strengthened. In addition, the main factors affecting China's AEE are fiscal expenditure, fertilizer intensity, pesticide intensity, and economic growth, whose multiyear average $\mathrm{q}$ values were greater than 0.35 .

With a multiyear average $q$ value of 0.6071 , fiscal expenditure is the leading factor affecting the AEE among all influencing factors. In China, the government policies on agriculture play an important role in agriculture sustainable development. The sustainable development of agriculture is a systematic and complex project, calling for massive funds from the government. The government's fiscal input is indispensable to elevating farmer income, improving agricultural infrastructure, accelerating development of agricultural resources, and enhancing eco-environmental protection. In 2000, China only spent 36.71 billion yuan on AFW affairs. Nineteen years later, the spending increased to $2,108.59$ billion yuan, up by more than 57 times.

With a multiyear average $q$ value of 0.4760 , fertilizer intensity is the second largest influencing factor of the AEE. Currently, Chinese agriculture bears the typical features of petroleum agriculture. The most prominent 


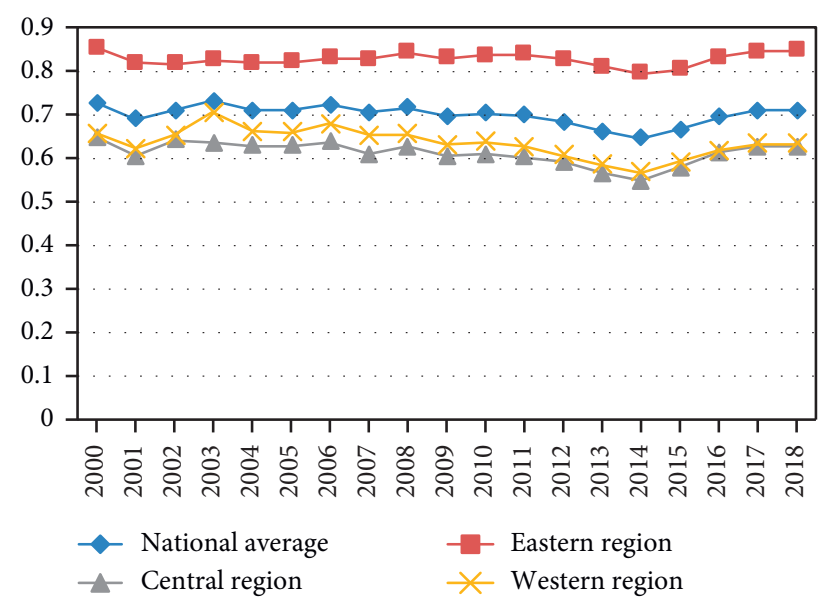

Figure 1: AEE trends across the country and in eastern, central, and western regions.

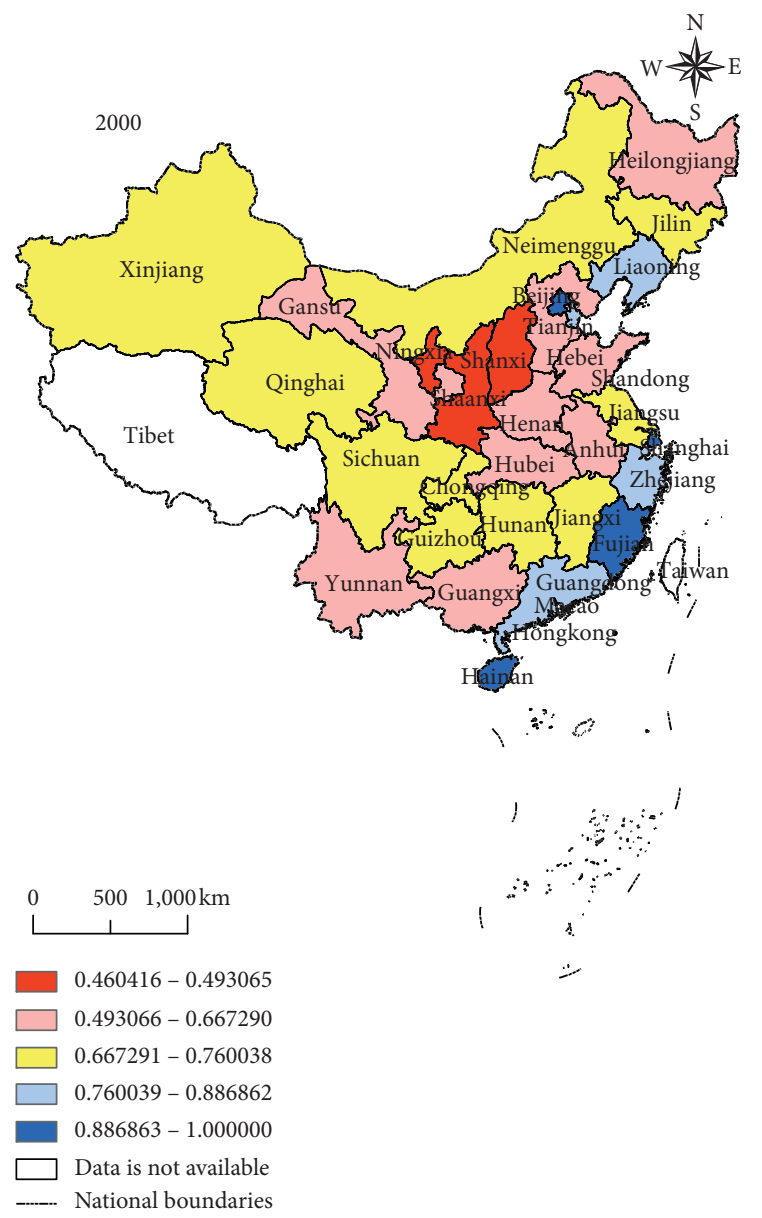

(a)

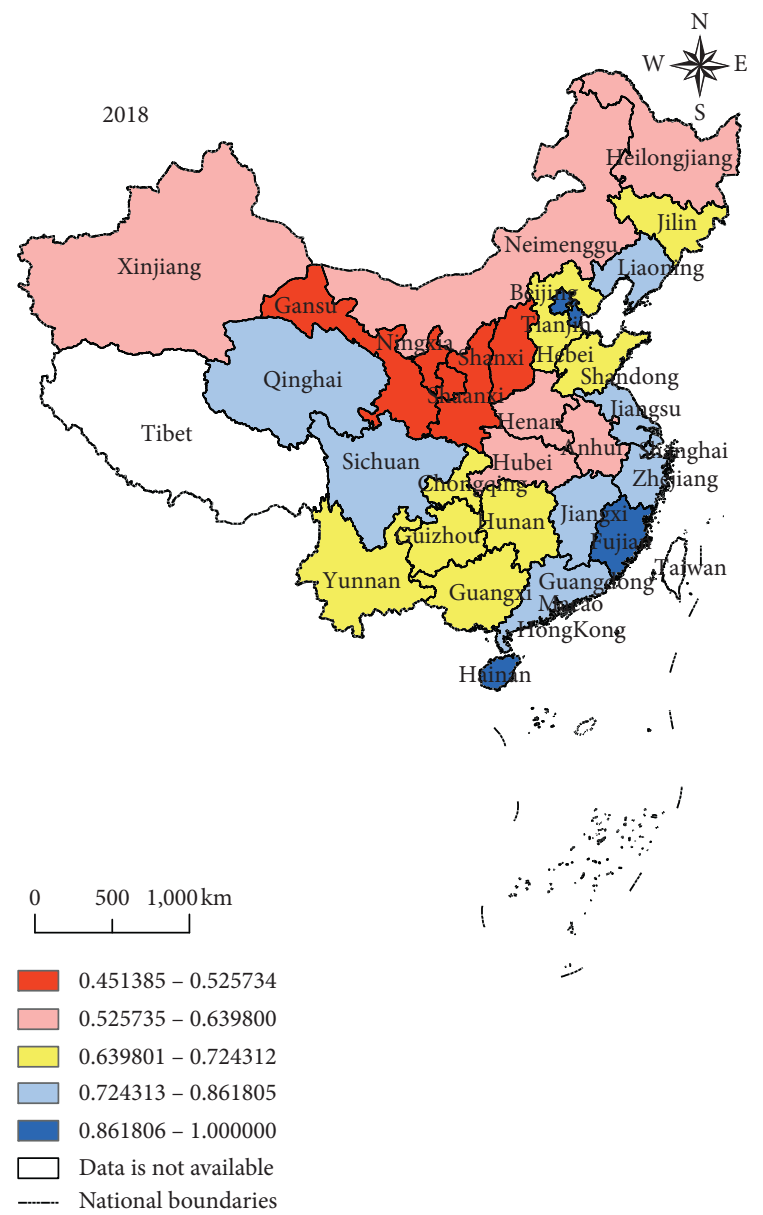

(b)

Figure 2: Spatiotemporal evolution of China's AEEs.

feature is the mass application of agricultural production materials like fertilizers. Despite promoting crop yield, increasing fertilizer intensity brings problems like soil hardening, fertility decline, non-point source pollution, and environmental degradation. To solve the eco-environmental problems in agricultural development, China must gradually reduce the fertilizer application and transform its agriculture from "petroleum agriculture" to "green agriculture."

With a multiyear average $q$ value of 0.4211 , pesticide intensity has a direct bearing on the AEE. Hoang and Nguyen [23] also found that a high pesticide intensity 
TABLE 4: Analysis results on AEE influencing factors.

\begin{tabular}{lcccccc}
\hline Ranking & 2000 & 2006 & 2012 & 2018 & Multiyear average & Trend of influence \\
& $q$ & $q$ & $q$ & $q$ & 0.3536 & $\downarrow$ \\
X1 & 0.6648 & 0.4465 & 0.3374 & 0.1147 & 0.1074 & $\downarrow$ \\
X2 & 0.2556 & 0.1901 & 0.2056 & 0.2026 & 0.4760 & $\uparrow$ \\
X3 & 0.2693 & 0.2535 & 0.2029 & 0.4051 & 0.4211 & $\downarrow$ \\
X4 & 0.4324 & 0.4632 & 0.3612 & 0.4814 & 0.2992 & $\downarrow$ \\
X5 & 0.3466 & 0.2487 & 0.2133 & 0.2161 & 0.2844 & $\downarrow$ \\
X6 & 0.1751 & 0.2788 & 0.2593 & 0.4257 & 0.6071 & $\downarrow$ \\
X7 & 0.2766 & 0.2484 & 0.5422 & 0.3979 & $\downarrow$ \\
\hline
\end{tabular}

reduces the environmental efficiency on farms. To effectively prevent agricultural pests, China has applied more and more pesticides in recent years. Admittedly, pesticides can alleviate agricultural pest harm to some extent. However, pesticide application leads to nonnegligible pollutions to the air, water, and soil. Apart from being a major source of agricultural greenhouse gases, pesticides could evaporate to the air, causing severe pollution to the air environment.

With a multiyear average $q$ value of 0.3536 , economic growth exerts an important impact on the AEE. This factor is a mixed blessing to the AEE. For one thing, farmers earn more thanks to economic growth and tend to buy more production materials like pesticides and fertilizers; the mass application of these materials will negatively affect the AEE. For another reason, with economic growth, farmers will gradually phase out traditional high-pollution production materials and switch to organic fertilizers and green pest control technologies, which help to promote the AEE. Regardless of the perspective, economic growth does have a nonnegligible influencing on agricultural eco-environment.

Furthermore, agricultural planting structure, agricultural scientific progress, and capitalization level have certain impacts on the AEE, but their impacts are not significant. Their multiyear average $q$ values were $0.2992,0.2844$, and 0.1074 , respectively. In the sample period, the three factors did not greatly improve the AEE. In future, the government policies should focus on optimizing agricultural planting structure, speeding up agricultural technology progress, and increasing fixed asset investment in agriculture.

\section{Conclusions}

This paper sets up an evaluation system for the AEE and evaluated the AEEs of 30 Chinese provinces with an SBM containing an undesired output. In addition, ArcGIS was adopted to analyze the spatiotemporal evolution of the AEE, and geodetector was implemented to examine the factors affecting the AEE. The results show the following:

(1) In the sample period, there is a huge provincial gap in AEE across China. Beijing, Hainan, Guangdong, Fujian, Liaoning, and Tianjin achieved desirable AEEs in the sample period, which averaged at above 0.8. Meanwhile, Hebei, Henan, Heilongjiang, Shaanxi, Anhui, Gansu, Shanxi, and Ningxia failed to achieve satisfactory AEEs in that period, which averaged at below 0.6 . Overall, most provinces with a high AEE belong to eastern coastal region, while most inland provinces had a relatively low AEE.

(2) In the sample period, the AEEs in eastern, central, and western regions followed basically the same trend. Except for a few years, the AEEs in these regions remained stable, without any significant changes. By the AEE, the three regions can be ranked in descending order as eastern region (0.8276), western region (0.6124), and central region (0.6356). That is, the eastern region had the highest AEE in the sample period, followed by the western region, while the central region ranked at the bottom.

(3) The results of spatiotemporal evolution show that, in terms of space, the spatial distribution of China's AEE changed with time; in particular, the high AEE provinces shifted towards the inland from eastern coastal region. In terms of time, the AEEs in most provinces were not satisfactory, despite some changes in the sample period, calling for further improvement in future.

(4) Geodetector results suggest that the multiyear average $q$ values of fiscal expenditure, fertilizer intensity, pesticide intensity, and economic growth stood at $0.6071,0.4760,0.4211$, and 0.3536 , respectively. These factors are the leading impactors on China's AEE. The AEE was also affected by agricultural planting structure, agricultural scientific progress, and capitalization level, but the effects of these three factors were not significant.

\section{Data Availability}

The data used in this article were obtained from the Statistical Yearbook published by the National Bureau of Statistics of China.

\section{Conflicts of Interest}

The author declares no conflicts of interest.

\section{Acknowledgments}

The author acknowledges the support from the National Natural Science Foundation of China (Grant no. 52000069) and Key R\&D and Promotion Projects in Henan Province (Grant no. 202102310608). 


\section{References}

[1] L. Shi, J. Zhou, and S. Liu, "Evaluation and drivers of green agricultural water use efficiency in Yangtze river economic zone," International Journal of Sustainable Development and Planning, vol. 15, no. 8, pp. 1333-1339, 2020.

[2] X. Geng, "On the regional differences in agricultural water use efficiency in China and their convergence," International Journal of Design \& Nature and Ecodynamics, vol. 15, no. 2, pp. 189-196, 2020.

[3] P. Liu, Z. Fang, C. Lv, and A. Ruan, “China's agricultural water-use efficiency and its influencing factors under the constraint of pollution emission," International Journal of Design \& Nature and Ecodynamics, vol. 15, no. 4, pp. 579-585, 2020.

[4] C. Thirtle, H. S. von Bach, and J. van Zyl, "Total factor productivity in South African agriculture, 1947-91," Development Southern Africa, vol. 10, no. 3, pp. 301-318, 1993.

[5] L. D. Tamini, B. Larue, and G. West, "Technical and environmental efficiencies and best management practices in agriculture," Applied Economics, vol. 44, no. 13, pp. 1659-1672, 2012.

[6] F. Greta, M. Alessandro, and P. Sara, "Environmental efficiency, productivity and public funds: the case of the Italian agriculture industry," Agricultural Systems, vol. 121, no. 1, pp. 73-80, 2013.

[7] V. W. Ruttan, "Productivity growth in world agriculture: sources and vonstrains," American Economic Association, vol. 16, no. 4, pp. 161-184, 2012.

[8] F. J. Arcelus and P. Arocena, "Productivity differences across OECD countries in the presence of environmental constraints," Journal of the Operational Research Society, vol. 56, no. 12, pp. 1352-1362, 2005.

[9] M. Nanere, I. Fraser, A. Quazi, and C D’Souza, "Environmentally adjusted productivity measurement: an Australian case study," Journal of Environmental Management, vol. 85, no. 2, pp. 350-362, 2007.

[10] A. Nin, C. Arndt, and P. V. Preckel, "Is agricultural productivity in developing countries really shrinking? new evidence using a modified nonparametric approach," Journal of Development Economics, vol. 71, no. 2, pp. 395-415, 2003.

[11] V.-N. Hoang and M. Alauddin, "Input-orientated data envelopment analysis framework for measuring and decomposing economic, environmental and ecological efficiency: an application to OECD agriculture," Environmental and Resource Economics, vol. 51, no. 3, pp. 431-452, 2012.

[12] G. Vlontzos, S. Niavis, and B. Manos, "A DEA approach for estimating the agricultural energy and environmental efficiency of EU countries," Renewable and Sustainable Energy Reviews, vol. 40, pp. 91-96, 2014.

[13] J. Fernandez-Cornejo and C. R. Shumway, "Research and productivity in Mexican agriculture," American Journal of Agricultural Economics, vol. 79, no. 3, pp. 738-753, 1997.

[14] G. Dono, R. Cortignani, L. Doro et al., "An integrated assessment of the impacts of changing climate variability on agricultural productivity and profitability in an irrigated mediterranean catchment," Water Resources Management, vol. 27, no. 10, pp. 3607-3622, 2013.

[15] T. Skevas, S. E. Stefanou, and A. O. Lansink, "Can economic incentives encourage actual reductions in pesticide use and environmental spillovers?," Agricultural Economics, vol. 43, no. 3, pp. 267-276, 2012.

[16] Z. Zhu and Y. Zheng, "Green total factor energy efficiency in China and its influencing factors," International Journal of
Sustainable Development and Planning, vol. 15, no. 5, pp. 781-787, 2020.

[17] M. Nanere, I. Fraser, A. Quazi, and C. D’Souza, "Environmentally adjusted productivity measurement: an Australian case study," Journal of Environmental Management, vol. 85, no. 2, pp. 350-362, 2007.

[18] A. Hailu and T. S. Veeman, "Non-parametric productivity analysis with undesirable outputs: an application to the Canadian pulp and paper industry," American Journal of Agricultural Economics, vol. 83, no. 3, pp. 605-616, 2001.

[19] K. Tone, "A slacks-based measure of efficiency in data envelopment analysis," European Journal of Operational Research, vol. 130, no. 3, pp. 498-509, 2001.

[20] J. F. Wang, X. H. Li, G. Christakos et al., "Geographical detectors-based health risk assessment and its application in the neural tube defects study of the heshun region, China," International Journal of Geographical Information Science, vol. 24, no. 1, pp. 107-127, 2010.

[21] J. M. Johnson, A. J. Franzluebbers, S. L. Weyers, and D. C. Reicosky, "Agricultural opportunities to mitigate greenhouse gas emissions," Environmental Pollution, vol. 150, no. 6, pp. 107-124, 2007.

[22] A. Dubey and R. Lal, "Carbon footprint and sustainability of agricultural production systems in Punjab, India, and Ohio, USA," Journal of Crop Improvement, vol. 23, no. 4, pp. 332-350, 2009.

[23] V.-N. Hoang and T. T. Nguyen, "Analysis of environmental efficiency variations: a nutrient balance approach," Ecological Economics, vol. 86, pp. 37-46, 2013. 